\title{
UICC-TNM and JSBS staging systems with extrahepatic cholangiocarcinoma
}

\author{
Viroj Wiwanitkit
}

Received: 8 April 2010 / Accepted: 15 April 2010/Published online: 3 June 2010

(C) Springer-Verlag 2010

Dear Editor,

I read the recent publication by Sasaki et al. with great interest. Sasaki et al. concluded that "Patients who underwent surgical resection were not evenly divided across UICC-TNM staging categories in comparison to JSBS staging. Stratification of survival ability was better when using the JSBS staging in comparison to the UICCTNM system [1]." I agree that JSBS might be a good classification system. However, there are still some remaining questions. In general, there are many other systems for the classification of cholangiocarcinoma including the American Joint Committee on Cancer, Bismuth-Corlette, and the modified Memorial Sloan-Kettering Cancer Center classification [2,3]. Additional comparative assessment of those systems will give useful data on making a decision in using the best classification system. Also, the cost and effectiveness of each system, which might be different due to system-specific criteria, should be focused and further cost-effectiveness analysis should be done.

Conflict of interest None

\section{References}

1. Sasaki R, Murata S, Oda T, Ohkohchi N, Takeda Y, Wakabayashi G (2010) Evaluation of UICC-TNM and JSBS staging systems for surgical patients with extrahepatic cholangiocarcinoma. Langenbecks Arch Surg (in press). doi:10.1007/s00423-010-0640-3

2. Kim HJ (2005) TNM staging of hilar cholangiocarcinoma. Korean J Gastroenterol 46(1):20-27

3. Chung YE, Kim MJ, Park YN, Lee YH, Choi JY (2008) Staging of extrahepatic cholangiocarcinoma. Eur Radiol 18(10):2182-2195
V. Wiwanitkit $(\bowtie)$

Wiwanitkit House,

Bangkhae,

Bangkok 10160, Thailand

e-mail: wviroj@yahoo.com 